\title{
FUNGSI TRADISI LISAN SUSURUNGAN \\ BAGI MASYARAKAT BANJAR HULU
}

\section{(THE FUNCTION OF ORAL TRADITION SUSURUNGAN FOR THE BANJAR HULU SOCIETY)}

\author{
Hestiyana \\ Balai Bahasa Provinsi Kalimantan Selatan \\ Jalan Jenderal A.Yani Km 32, 2 Loktabat Utara Banjarbaru 70712, Kalimantan Selatan \\ Pos-el: hestiyana21@gmail.com
}

Diterima: 30 April 2015; direvisi: 25 Agustus; disetujui: 20 Desember 2015

\begin{abstract}
This study aimed to describe the function of the oral tradition for the community susurungan Banjar Hulu. The method used in this research is descriptive qualitative method. Techniques are being made to collect data recording technique and technique are noted. Data processing procedures performed by four stages, namely: (1) the transcription of recorded data, (2) classification of data, (3) the translation of data, and (4) analyzing the data. Source of data in this study using: (1) primary data, ie data obtained from informants in the field as much as 4 people were categorized as speakers oral tradition susurungan residing in Hulu Sungai Selatan, Hulu Sungai Tengah, Hulu Sungai Utara, and District Tabalong; and (2) secondary data, which complement the data obtained from the results of existing research related to the study of oral tradition Banjar Hulu susurungan. From the results of the primary data source in the field of recording the results obtained, as many as 27 utterances. However, in the stage of data analysis just presented the results of the speech text which is considered to represent each function susurungan. The research found there are three functions susurungan oral tradition for the people of Banjar Hulu, namely: (1) function to test the intelligence susurungan person, 2) function susurungan to pass the time during the vigil keeping the corpse, and 3) the function susurungan to exceedothers.
\end{abstract}

Keywords: function, susurungan oral literature, Banjar Hulu society

\begin{abstract}
Abstrak
Penelitian ini bertujuan untuk mendeskripsikan fungsi tradisi lisan susurungan bagi masyarakat Banjar Hulu. Metode yang digunakan dalam penelitian ini adalah metode deskriptif kualitatif. Teknik yang dilakukan untuk mengumpulkan data adalah teknik rekam dan teknik catat. Prosedur pengolahan data dilakukan dengan empat tahapan, yaitu: (1) transkripsi rekaman data, (2) klasifikasi data, (3) penerjemahan data, dan (4) menganalisis data. Sumber data dalam penelitian ini adalah: (1) data primer, yaitu data yang diperoleh dari informan di lapangan sebanyak 4 orang yang dikategorikan sebagai penutur tradisi lisan susurungan yang bertempat tinggal di Kabupaten Hulu Sungai Selatan, Kabupaten Hulu Sungai Tengah, Kabupaten Hulu Sungai Utara, dan Kabupaten Tabalong; dan (2) data sekunder, yaitu data pelengkap yang diperoleh dari hasil penelitian yang sudah ada yang terkait dengan penelitian tradisi lisan Banjar Hulu susurungan. Dari hasil sumber data primer di lapangan diperoleh hasil perekaman, yaitu sebanyak 27 tuturan. Akan tetapi, dalam tahap analisis data hanya disajikan hasil teks tuturan yang dianggap mewakili masing-masing fungsi susurungan. Hasil penelitian ditemukan ada tiga fungsi tradisi lisan susurungan bagi masyarakat Banjar Hulu, yaitu(1) fungsi susurungan untuk menguji kepandaian seseorang, 2) fungsi susurungan untuk mengisi waktu pada saat bergadang menjaga jenazah, dan 3) fungsi susurungan untuk dapat melebihi orang lain.
\end{abstract}

Kata kunci: fungsi, tradisi lisan susurungan, masyarakat Banjar Hulu 


\section{Pendahuluan}

Salah satu bentuk sastra daerah yang keberadaannya menjadi kekayaan budaya adalah tradisi lisan. Tradisi lisan akan terus ada dan melekat di hati masyarakat pemiliknya apabila dijadikan norma-norma dan fungsi dalam kehidupan masyarakat. Endraswara (2009:235) menyebut istilah tradisi ini yang sering meliputi sastra lisan. Sastra lisan itu adalah sastra rakyat. Sastra rakyat memiliki tradisi turun-temurun. Kemudian, Endraswara (2009:235) menambahkan bahwa sastra lisan itu meliputi: teka-teki (riddles), peribahasa (provebs), kutukan (curses), mantra gunaguna (charms), kata yang sulit diucapkan seperti rajah (tonguetwisters), permainan kata-kata (puns), dan lain-lain.

Tradisi lisan hadir berdasarkan konsepsi-konsepsi yang hidup dalam alam pikiran sebagian besar warga masyarakat. Masyarakat menganggap tradisi lisan mempunyai nilai hidup. Oleh karena itu, sistem nilai ini mempunyai fungsi dan sebagai pedoman tertinggi bagi manusia. Tradisi lisan diwujudkan secara kompleks dalam ide, gagasan, nilai-nilai norma, aktivitas manusia, hasil karya manusia dan sebagainya. Dengan kata lain tradisi atau sastra lisan adalah segala wacana yang diucapkan melalui lisan, karena tradisi disebarkan melalui lisan maupun tulisan dengan tujuan mengingat dan meneruskan tradisi lisan (Tisnasari, 2013:161).

Salah satu tradisi lisan masyarakat Banjar yang masih berlangsung sampai sekarang adalah tradisi lisan berbentuk susurungan (teka-teki). Tradisi atau sastra lisan susurungan ini disampaikan dalam bahasa Banjar Hulu yang dituturkan dari mulut ke mulut. Sastra lisan Banjar Hulu itu sendiri didefinisikan sebagai karya imajinatif, diucapkan, dan menggambarkan keadaan alam, adat istiadat, budaya dan kehidupan sosial orang Banjar Hulu dengan menggunakan bahasa sebagai mediumnya (Asmuni, 2014:3).

Susurungan merupakan istilah sastra lisan yang berkembang di masyarakat Banjar Hulu. Kata susurungan dibentuk dari bentuk dasar surungan yang mengalami pengulangan sebagian. Selain istilah susurungan (tekateki) dikenal juga istilah sasurungan yang berkembang pada masyarakat Banjar Kuala. Dalam Kamus Bahasa Banjar (Hapip, 2006:175) disebutkan bahwa sasurungan adalah teka-teki. Pendapat yang sama juga dikemukakan oleh Mugeni, dkk (2008:243) bahwa sasurungan adalah teka-teki. Kata sasurungan dan susurungan dibentuk dari bentuk dasar surungan yang mengalami pengulangan sebagian. Hanya saja, pengulangan sebagian yang berkembang pada masyarakat Banjar Kuala mengalami perubahan bunyi menjadi sa sehingga terbentuklah kata sasurungan, sedang pada masyarakat Banjar Hulu adalah su sehingga menjadi susurungan. Selain susurungan, masyarakat Banjar sering pula menyebut teka-teki lisan tradisional ini dengan cacapatian, cucupatian, dan tatangguhan.

Dengan demikian, susurungan sebagai bagian dari sastra lisan Banjar tentunya dapat dipahami sebagai sebuah tradisi sastra yang mempunyai manfaat dalam kehidupan masyarakat pendukungnya. Susurungan menjadi pedoman kehidupan masyarakat Banjar Hulu karena mengandung nilai-nilai luhur. Sastra lisan susurungan ini disampaikan dalam bahasa Banjar Hulu.

Bahasa Banjar merupakan bahasa yang digunakan dalam kehidupan sehari-hari masyarakat Banjar di Kalimantan Selatan dan yang paling dominan dituturkan oleh suku Banjar. Hapip (2006:xi) mengemukakan bahwa bahasa Banjar ialah bahasa yang dipergunakan oleh suku Banjar. Pendapat yang sama juga dikemukakan Kawi (2002:9) bahwa bahasa Banjar merupakan kelompok bahasa Melayu dan 
bukan kelompok bahasa-bahasa Dayak. Akan tetapi, dalam perkembangannya bahasa Banjar banyak dipengaruhi oleh bahasa lain. Kemudian, Hapip (2006:xi) membagi bahasa Banjar menjadi dua dialek besar, yaitu: (1) dialek bahasa Banjar Kuala dan (2) dialek bahasa Banjar Hulu. Dialek bahasa Banjar Kuala umumnya dipakai oleh penduduk asli sekitar kota Banjarmasin, Martapura, dan Pelaihari. Dialek bahasa Banjar Hulu adalah bahasa Banjar yang dipakai oleh penduduk di daerah Hulu Sungai umumnya, seperti daerah Kabupaten Tapin, Hulu Sungai Selatan, Hulu Sungai Tengah, Hulu Sungai Utara, Kabupaten Balangan, dan Kabupaten Tabalong.

Sastra lisan yang terdapat di Kalimantan Selatan juga merupakan bentuk kesusastraan yang menjadi bagian dari folklor. Danandjaja (2002:2) mengatakan bahwa folklor adalah sebagian kebudayaan suatu kolektif yang tersebar dan diwariskan secara turun-temurun. Setiap sastra lisanyang terdapat di suatu masyarakat tentulah memiliki fungsi bagi kehidupan masyarakat pemiliknya.

Sastra lisan tidak hanya berfungsi sebagai hiburan semata. Akan tetapi, sastra lisan juga berfungsi sebagai alat untuk mengajarkan nilai-nilai moral. Dalam sastra lisan terkandung muatan nilai moral yang diyakini dapat menjadi norma-norma dalam masyarakat. Secara tidak langsung, melalui sastra lisan juga mendidik masyarakat pemilik sastra lisan tersebut. Dengan kata lain, sastra lisan bertujuan untuk mengemukakan dan menyampaikan maksud tertentu, seperti nasihat-nasihat dan nilainilai moral. Sastra lisan susurungan ini juga mengandung norma-norma sosial yang berlaku dalam masyarakat Banjar Hulu yang digunakan orang tua dalam mendidik anak.

Fungsi sastra lisan dalam masyarakat antara lain mengetahui apakah peranan sastra di dalam masyarakat. Jika sastra berperan dalam masyarakat, sedikit ataukah banyak ia mencerminkan keadaan budaya dan tata susunan masyarakat? Jika sastra lisan merefleksikan keadaan masyarakat, apakah yang direfleksikan itu (Hutomo, 1991:18). Dengan demikian, penelitian ini menganalisis fungsi yang terdapat dalam tradisi lisan susurungan bagi masyarakat Banjar Hulu.

Sejauh ini, penelitian mengenai sastra lisan susurungan belum pernah dilakukan. Akan tetapi, penelitian yang serupa yakni mengenai cucupatian sudah pernah dilakukan hanya saja hingga saat ini jumlahnya masih sedikit. Penelitian tentang cucupatian yang pernah dilakukan adalah Sastra Lisan Banjar: Cucupatian (2009) dan penelitian yang berjudul Cucupatian Banjar (2011) dilakukan oleh Yayuk.

Penelitian yangdilakukan olehYayuk (2009) dengan judul Sastra Lisan Banjar: Cucupatian membahas kata tanya yang digunakan dalam cucupatian Banjar, cucupatian bahasa Banjar berdasarkan jenis tema yang dikandungnya, dan jawaban cucupatian berdasarkan sifatnya. Kemudian, penelitian yang berjudul Cucupatian Banjar (2011) membahas cucupatian dalam masyarakat Banjar yang dibagi dalam enam tema, yaitu: (1) cucupatian Banjar dengan tema hewan, (2) cucupatian Banjar dengan tema alam sekitar, (3) cucupatian Banjar dengan tema manusia dan aktivitasnya, (4) cucupatian Banjar dengan tema makanan, (5) cucupatian Banjar dengan tema peralatan, serta (6) cucupatian Banjar dengan tema buah dan tumbuh-tumbuhan. Kedua penelitian tersebut hanya sebatas membahas kata tanya yang digunakan dan jawaban dalam cucupatian Banjar, serta masih bersifat pengklasifikasian tema cucupatian Banjar sehingga masih bersifat umum. Selain itu, kajian cucupatian yang telah dilakukan tersebut tidak membedakan cucupatian yang masih digunakan masyarakat Banjar Hulu dan masyarakat Banjar Kuala. Berbeda dengan penelitian 
Fungsi Tradisi Lisan...(Hestiyana)| 91

terhadap fungsi tradisi lisan susurungan bagi masyarakat Banjar Hulu ini yang khusus membahas susurungan (teka-teki) yang terdapat di masyarakat Banjar Hulu.

Kajian fungsi tradisi lisan susurungan ini lebih mendalam dari penelitian sebelumnya karena menelusuri dan membahas fungsi sastra lisan susurungan yang masih hidup dan berkembang dalam kehidupan masyarakat Banjar Hulu. Mengingat keberadaan sastra lisan susurungan dalam keadaan terancam punah, perlu dilakukan kajian terhadap sastra lisan susurungan tersebut. Sekarang ini, sastra lisan susurungan sudah jarang dituturkan, terutama oleh generasi muda. Padahal, sastra lisan susurungan mempunyai nilai-nilai moral dan norma-norma sosial yang perlu kita peliharadan lestarikan.

Keberadaan sastra lisan Banjar Hulu sekarang ini sangat dikhawatirkan karena selama ini masih sedikit usaha yang dilakukan untuk menggali dan menyusunnya sebagai dokumen yang lengkap. Padahal jumlah sastra lisan Banjar Hulu masih cukup banyak. Hal ini disebabkan kurangnya minat generasi muda terhadap sastra lisan serta yang sering menggunakan sastra lisan adalah orang-orang yang berusia lanjut. Selain itu, kekayaan sastra daerah akan pudar jika tidak dilestarikan. Ini menjadi kajian menarik, agar sastra lisan susurungan tidak punah dan hilang dengan sendirinya. Melalui penelitian ini, akan diungkapkan fungsi tradisi lisan susurungan bagi masyarakat Banjar Hulu dengan harapan agar dapat terus dilestarikan serta diwariskan kepada generasi selanjutnya.

Penelitian sastra lisan perlu dilakukan terus-menerus untuk memahami dan mengetahui masyarakat yang melahirkan sastra lisan tersebut, seperti penelitian fungsi tradisi lisan susurungan ini sebagai ragam dari sastra lisan Banjar Hulu yang masih hidup. Dengan mengkaji sastra lisan kita dapat mengungkapkan kehidupan masyarakat Banjar Hulu yang dapat dijadikan pelajaran bagi generasi penerus.

Pengkajian tentang tradisi lisan susurungan ini membuktikan bahwa masyarakat Banjar Hulu di Kalimantan Selatan memiliki kekayaan budaya yang layak diteliti. Kajian fungsi tradisi lisan susurungan juga akan menambah kekayaan penelitian sastra lisan. Selain itu, kajian tradisi lisan susurungan ini sangat menarik untuk diuraikan dan dibahas karena bermanfaat bagi teori pengkajian sastra lisan nusantara.

\section{Kerangka Teori}

Sastra lisan merupakan hasil sastra yang diturunkan dari mulut ke mulut dan dapat dijadikan pedoman bagi kehidupan masyarakat pemiliknya. Tuloli (Amir, 2013:43) menyatakan bahwa sastra lisan adalah salah satu gejala kebudayaan yang terdapat pada masyarakat terpelajar dan yang belum terpelajar. Sastra lisan harus dibicarakan dalam hubungan dengan pencerita, penceritaan, dan pendengar atau penontonnya. Selanjutnya, Tuloli (Amir, 2013:44) mengatakan bahwa sastra lisan berubah sesuai dengan dinamika masyarakat pemiliknya. Usaha pelestarian perlu dilaksanakan karena perubahan kepunahan sastra lisan tidak akan pernah berhenti. Jika sastra lisan hilang atau punah, kekayaan budaya di dalamnya akan punah pula atau berubah. Bartlett (1965:244-245) mengemukakan bahwa sastra lisan merupakan sastra yang diperdengarkan. Jadi, sastra lisan merupakan kekayaan daerah yang harus mendapat perhatian dan nilainilai yang terdapat di dalamnya harus terus pula digali.

Menurut Danandjaja (2002:21-22), tradisi lisan adalah yang bentuknya memang murni lisan. Bentuk-bentuk (genre) folklor yang termasuk ke dalam kelompok besar ini, antara lain: (a) bahasa rakyat (folk speech) seperti logat, julukan, pangkat 
tradisional, dan titel kebangsawanan; (b) ungkapan tradisional seperti peribahasa, pepatah, dan pemeo; (c) pertanyaan tradisional, seperti teka-teki; (d) puisi rakyat, seperti pantun, gurindam, dan syair; (e) cerita prosa rakyat, seperti mite, legenda, dan dongeng, dan (f) nyanyian rakyat.

Taum (2011:21) merumuskan sebuah definisi kerja (hypothetical definition) bahwa sastra lisan adalah sekelompok teks yang disebarkan dan diturun-temurunkan secara lisan, yang secara intrinsik mengandung sarana-sarana kesusastraan dan memiliki efek estetik dalam kaitannya dengan konteks moral maupun kultur dari sekelompok masyarakat tertentu. Selanjutnya, Taum (2011:24-25) mengemukakan bahwa sastra lisan yang merupakan bagian dari folklore atau tradisi lisan memiliki ciri-ciri tertentu, yaitu: (1) sastra lisan adalah teks sastra yang dituturkan secara lisan; (2) sastra lisan hadir dalam berbagai bahasa daerah; (3) sastra lisan selalu hadir dalam versi-versi dan varian-varian yang berbeda-beda; (4) sastra lisan bertahan secara tradisional dan disebarkan dalam bentuk standar/relatif tetap dalam kurun waktu yang cukup lama, paling kurang dua generasi; (5) sastra lisan memiliki konvensi dan poetikanya sendiri.

Endraswara (2013:151) mengemukakan bahwa sastra lisan adalah karya yang penyebarannya disampaikan dari mulut ke mulut secara turun temurun. Ciri-ciri sastra lisan, yakni: (1) lahir dari masyarakat yang polos, belum melek huruf, dan bersifat tradisional; (2) menggambarkan budaya milik kolektif tertentu, yang tak jelas siapa penciptanya; (3) lebih menekankan aspek khayalan, ada sindiran, jenaka, dan pesan mendidik; (4) sering melukiskan tradisi kolektif tertentu. Di samping ciri-ciri tersebut, ada ciri lain yang agak umum, yakni: (1) sastra lisan banyak mengungkapkan kata-kata atau ungkapan- ungkapan klise dan (2) sastra lisan sering bersifat menggurui.

Hutomo (1991:3 - 4) menyatakan bahwa sastra lisan memiliki ciri, antara lain: 1) penyebarannya melalui mulut, maksudnya ekspresi budaya yang disebarkan baik dari segi waktu maupun ruang melalui mulut; 2) lahir dari masyarakat yang masih bercorak desa, masyarakat di luar kota, atau masyarakat yang belum mengenal huruf; 3) menggambarkan ciri-ciri budaya satu kelompok masyarakat; 4) bercorak puitis; 5) terdiri dari berbagai versi; 6) tidak mementingkan fakta atau kebenaran, lebih menekankan pada aspek khayalan, fantasi yang tidak diterima oleh masyarakat modern, tetapi mempunyai fungsi di masyarakat, dan 7) menggunakan bahasa lisan setiap hari.

Dengan demikian, sastra lisan merupakan hasil ekspresi kesusastraan yang disebarkan dari mulut ke mulut secara turuntemurun yang mengandung nilai-nilai moral. Dalam sastra lisan nilai-nilai moral tersebut diyakini dapat menjadi norma-norma dalam masyarakat serta menjadi ciri budaya masyarakat pemiliknya.

Sastra lisan sebagai hasil sastra suatu masyarakat memiliki kedudukan dan fungsifungsi tersendiri dalam masyarakat pemakainya, baik dalam masyarakat masa lalu, maupun masyarakat masa sekarang. Sudikan (2001:109-112) menyatakan bahwa teori fungsi itu dipelopori oleh para ahli folklor, diantaranya William R Bascom, Alan Dundes, dan Ruth Finnegan. Menurut Bascom dalam Danandjaja (2002: 19) sastra lisan mempunyai empat fungsi, yaitu: (a) sebagai sistem proyeksi (projective system), yakni sebagai alat pencermin angan-angan suatu kolektif; (b) sebagai alat pengesahan pranata-pranata dan lembaga-lembaga kebudayaan; (c) sebagai alat pendidikan anak (pedagogical device); dan (d) sebagai alat pemaksa dan pengawas agar norma- 
norma masyarakat akan selalu dipatuhi anggota kolektifnya.

Selanjutnya, Alan Dundes

(Danandjaja, 2002:45) mengemukakan fungsi yang dibagi menjadi lima, yaitu: (1) untuk menguji kepandaian seseorang, (2) untuk meramal, (3) sebagai bagian dari upacara perkawinan, (4) untuk mengisi waktu pada saat bergadang menjaga jenazah, dan (5) untuk dapat melebihi orang lain.

Sastra lisan mempunyai fungsi dalam kehidupan masyarakat, untuk hiburan. Amir (2013:34) mengemukakan bahwa fungsi sastra lisan sebagai hiburan atau membuat masyarakat terhibur. Endraswara (2013:157) mengatakan bahwa sastra lisan memang kaya makna dan menghibur sekaligus mengasah otak penikmat. Di samping memuat makna dan fungsi hiburan, sastra lisan juga memuat aspek-aspek sindiran.

Teeuw (1988:304) mengatakan bahwa selain mengandung fungsi estetik, sastra lisan juga mengandung fungsi-fungsi lain seperti agama dan sosial yang masih terbuka untuk penelitian-penelitian ilmiah. Selanjutnya, Teeuw (1988:444) menambahkan bahwa di dalam masyarakat niraksara, sastra lisan bahkan berfungsi sebagai wadah kalimat tradisional yang mengandung adat-istiadat, konversi, sistem nilai dan berbagai norma yang berlaku dalam masyarakat tersebut.

Hutomo dalam Endraswara (2009:125) memberikan konsep fungsi. Dalam pandangannya, fungsi ialah 'kaitan saling ketergantungan, secara utuh dan berstruktur, antara unsur-unsur sastra, tulis atau lisan, baik di dalam sastra itu sendiri (intern), maupun dengan lingkungannya (ekstern), tanpa membedakan apakah unsurunsur tersebut dipergunakan untuk memenuhi kebutuhan naluri manusia, ataupun memelihara keutuhan dan sistem struktur sosial'. Dari berbagai konsep teoritis fungsi di atas, penelitian ini akan mencoba menerapkan teorinya Alan Dundes untuk mengkaji fungsi tradisi lisan susurungan bagi masyarakat Banjar Hulu.

\section{Metode Penelitian}

Metode yang digunakan dalam penelitian ini adalah metode deskriptifkualitatif karena bertujuan untuk mendeskripsikan fungsi yang terkandung dalam tradisi lisan susurungan. Penggunaan metode kualitatif tersebut dilakukan karena data yang dihasilkan adalah data deskriptif berupa tuturan-tuturan lisan dari penutur. Endraswara (2013:154) mengemukakan bahwa pada dasarnya ada tiga tahap dalam penelitian sastra lisan. Pertama, pengumpulan data, yaitu melalui rekaman. Kedua, penggolongan (klasifikasi), yaitu memilah-milahkan data sesuatu dengan kelompoknya, kategori pengelompokkan bersifat natura. Ketiga, analisis, mempergunakan beberapa teori jika bersifat positivistik dan tanpa teori jika bersifat naturalistik.

Berdasarkan metode tersebut, maka teknik yang dilakukan untuk mengumpulkan data adalah teknik rekam dan teknik catat. Teknik rekam dilakukan dengan cara merekam tuturan sastra lisan susurungan dengan menggunakan alat bantu tape recorder. Hal ini mengingat apabila data yang diperoleh tersebut masih menimbulkan keraguan atau masih mengandung kesalahan, maka rekaman tersebut dapat diperdengarkan kembali. Teknik catat dimaksudkan untuk mencatat semua data yang diperoleh melalui perekaman, kemudian diwujudkan dalam bentuk teks tertulis. Selain itu teknik catat juga digunakan untuk mencatat hal-hal yang dianggap penting di luar data rekam untuk mendapatkan informasi tambahan.

Selanjutnya, prosedur pengolahan data dilakukan dengan empat tahapan. Pertama, transkripsi rekaman data, yaitu memindahkan data dalam bentuk tulisan yang sebenarnya. Dalam hal ini data sastra 
lisan susurungan yang telah diperoleh dipindahkan ke dalam bentuk data tulisan. Kedua, klasifikasi data, yaitu semua data dikumpulkan sesuai dengan klasifikasi berdasarkan isi. Data sastra lisan susurungan yang sudah berbentuk teks dikumpulkan sesuai dengan karakteristiknya dan dilakukan klasifikasi berdasarkan isinya. Ketiga, penerjemahan data, yaitu semua data yang telah dikelompokkan langsung diterjemahkan ke dalam bahasa Indonesia. Tuturan sastra lisan susurungan dalam bahasa Banjar Hulu diterjemahkan ke dalam bahasa Indonesia. Keempat, menganalisis data, yaitu menganalisis semua data yang terkumpul berdasarkan fungsi tradisi lisan susurungan bagi masyarakat Banjar Hulu.

Menurut Arikunto (2006:135), sumber data dapat dikelompokkan menjadi dua bagian, antara lain: (1) data primer, yaitu data pokok, dalam hal ini berupa tuturan tradisi lisan susurungan yang dikumpulkan dari narasumber yang diperoleh dari hasil dokumentasi, rekaman, serta wawancara; dan (2) data sekunder, yaitu data pelengkap yang diperoleh dari hasil penelitian yang sudah ada yang terkait dengan penelitian tradisi lisan Banjar Hulu susurungan.

Sumber data primer dalam penelitian ini adalah informan di lapangan sebanyak 4 orang yang dikategorikan sebagai penutur tradisi lisan susurungan yang bertempat tinggal di Kabupaten Hulu Sungai Selatan, Kabupaten Hulu Sungai Tengah, Kabupaten Hulu Sungai Utara, dan Kabupaten Tabalong. Hal ini mengacu kepada pendapat yang dikemukakan oleh Endraswara (2013:156) bahwa kajian sastra lisan, seharusnya tidak hanya berhenti pada klasifikasi data di lapangan saja. Namun, harus sampai pada fungsi sastra lisan itu sendiri. Fungsi dapat dilacak dengan menggunakan penafsiran yang dapat digali dari informan. Dari hasil sumber data primer di lapangan diperoleh hasil perekaman, yaitu sebanyak 27 tuturan. Akan tetapi, dalam tahap analisis data hanya disajikan hasil teks tuturan yang mewakili masing-masing fungsi. Hal ini dianggap beberapa data teks tuturan tersebut sudah mewakili data secara absah.

Untuk menjaga keabsahan data-data dalam penelitian ini, maka penentuan informan ditetapkan sebagai berikut.

1. Informan adalah suku Banjar Hulu.

2. Informan berusia antara 25-60 tahun.

3. Informan memahami tradisi lisan susurungan dan masih menggunakan tradisi lisan susurungan.

4. Informan menguasai bahasa Banjar Hulu dan bahasa Indonesia.

5. Informan adalah orang yang asyik diajak bicara agar dapat lebih dalam menggali informasi sastra lisan susurungan.

\section{Pembahasan}

Dalam menganalisis fungsi tradisi lisan susurungan digunakan analisis Alan Dundes (Danandjaja, 2002:45) yang membagi menjadi lima, yaitu: (1) untuk menguji kepandaian seseorang, (2) untuk meramal, (3) sebagai bagian dari upacara perkawinan, (4) untuk mengisi waktu pada saat bergadang menjaga jenazah, dan (5) untuk dapat melebihi orang lain. Untuk keefektifan hasil analisis data, maka akan digunakan singkatan $P$ untuk menyatakan pertanyaan dan singkatan $J$ untuk menyatakan jawaban.

Hasil penelitian menunjukkan bahwa fungsi tradisi lisan susurungan bagi masyarakat Banjar Hulu hanya ditemukan tiga fungsi, yaitu: (1) untuk menguji kepandaian seseorang, (2) untuk mengisi waktu pada saat bergadang menjaga jenazah, dan (3) untuk dapat melebihi orang lain. Berikut hasil analisis fungsi tradisi lisan susurungan bagi masyarakat Banjar Hulu. 


\subsection{Fungsi Susurungan untuk Menguji Kepandaian Seseorang}

Bagi masyarakat Banjar Hulu, susurungan berfungsi untuk menguji kepandaian seseorang. Susurungan sering dijadikan sarana bagi penutur bahasa Banjar Hulu untuk mengetahui sejauh mana lawan bicara mampu menjawab atau berpikir bila ada orang yang menuturkan susurungan. Sastra lisan susurungan ini juga digunakan penutur bahasa Banjar Hulu untuk menguji kepandaian lawan bicara dengan cara berpikir yang logis maupun secara logika. Berikut hasil analisisnya.

P: Cuba tangguh, pintar mana itik atawa sapi?

"Coba tebak, pandai mana itik atau sapi?"

J: Pintar itik karana itik kawa maulah hintalu mata sapi, sapi kada kawa maulah hintalu mata itik.

"Pandai itik karena itik bisa membuat telur mata sapi, sedangkan sapi tidak bisa membuat telur mata itik."

Pertanyaan susurungan (1) di atas mengacu pada perbandingan hewan itik dan sapi, yaitu itik atau sapi yang lebih pandai. Tentu saja, kedua hewan ini tidak bisa dibandingkan dari segi kepandaiannya, kecuali dari segi fisik. Akan tetapi, penanya sengaja mengajukan pertanyaan susurungan ini untuk menguji cara berpikir seseorang secara logika. Ternyata, jawaban yang dituturkan penjawab memang benar secara logika, yaitu lebih pandai itik karena bisa membuat telur mata sapi dan sapi tidak bisa membuat telur mata itik.Dalam masyarakat Banjar Hulu, memang ada istilah untuk telur yang sudah masak, yaitu telur mata sapi dan tidak ada istilah telur mata itik.

\section{(2) P: Buah nangapa nah nang paling}

banyak manapaatnya?

"Buah apa ya yang paling banyak manfaatnya?"

$\mathrm{J}$ : Buah tiwadak karana isinya kawa dimakan, biginya kawa dijarang gasan dimakan, kulitnya diulah mandai gasan dimakan jua, wan kulit luarnya gasan gagaru balakang.

"Buah cempedak karena isinya bisa dimakan, bijinya bisa direbus untuk dimakan, kulitnya dibuat mandai untuk dimakan juga, dan kulit luarnya untuk menggaruk punggung."

Pertanyaan susurungan (2) di atas berfungsi untuk menguji kepandaian seseorang dengan menanyakan buah yang mempunyai manfaat paling banyak. Secara ilmiah, orang mendengar susurungan tersebut akan berpikir bahwa nama buah yang buahnya saja memiliki banyak manfaat. Akan tetapi, ternyata jawabannya buah tiwadak 'buah cempedak' dan bukan buahnya saja yang memiliki manfaat karena mengandung banyak vitamin yang baik bagi tubuh, tetapi juga bijinya bisa direbus untuk dimakan, kulitnya dibuat mandai untuk dimakan sebagai lauk. Secara logika, kulit luar buah cempedak dikatakan bisa untuk menggaruk punggung."

(3) P: Apa bidanya sapi Japang lawan sapi nang ada di Indonesia?

"Apa bedanya sapi Jepang dengan sapi yang ada di Indonesia?"

J: Sapi Japang kawa makan rumput nang ada di Indonesia, sapi nang ada di Indonesia kada kawa makan rumput Japang.

"Sapi Jepang bisa makan rumput yang ada di Indonesia, sapi yang ada di Indonesia tidak bisa makan rumput Jepang." 
Pertanyaan susurungan (3) di atas berfungsi untuk menguji kepandaian seseorang. Bagi siapa saja yang mendengar susurungan tersebut akan berpikir dan mencari perbedaaan antara sapi Indonesia dan sapi Jepang. Perbedaan tersebut bisa dilihat dari fisik sapi. Ternyata jawabannya tidak secara ilmiah, tetapi untuk menguji kepandaian untuk bisa berpikir secara logika. Sapi Jepang bisa makan rumput di Indonesia, sedangkan sapi Indonesia tidak bisa makan rumput Jepang. Yang dimaksud dengan rumput Jepang dari pertanyaan susurungan adalah tali plastik karena masyarakat Banjar Hulu menyebut tali plastik sebutan rumput Jepang.

\subsection{Fungsi Susurungan untuk Mengisi Waktu pada Saat Bergadang Menjaga Jenazah}

Sastra lisan susurungan berfungsi untuk mengisi waktu pada saat bergadang menjaga jenazah.Bagi masyarakat Banjar Hulu, pertanyaan susurungan ini dituturkan dengan tujuan mengurangi kesedihan keluarga ataupun kerabat yang ditinggalkan. Selain itu, susurungan ini juga berfungsi agar orang-orang yang menjaga jenazah tidak mengantuk dan dapat menjalankan tugasnya menunggui jenazah hingga pagi hari. Berikut hasil analisisnya.

$$
\begin{array}{ll}
\text { P: Amun dibungkus bukannya } \\
\text { bungkusan, amun dipatak } \\
\text { bukannya tanaman, apa nah? } \\
\text { "Kalau dibungkus bukannya } \\
\text { bungkusan, kalau ditanam } \\
\text { bukannya tanaman, apa ya?" } \\
\mathrm{J}: \text { Mayat } \\
\text { "Mayat." }
\end{array}
$$

Ketika orang mendengar pertanyaan susurungan amun dibungkus bukannya bungkusan, amun dipatak bukannya tanaman "kalau dibungkus bukannya bungkusan, kalau dibenam bukannya tanaman" akan berpikir bahwa sesuatu yang sering dibungkus biasanya disebut bungkusan dan tanaman akan ditanam di dalam tanah. Hal ini tentu membuat orang yang mendengar pertanyaan susurungan tersebut menjadi bingung, apalagi bagi orang yang baru pertama mendengar susurungan tersebut.

Ternyata jawaban dari pertanyaan susurungan tersebut adalah mayat. Jawaban tersebut diterima oleh orang yang mendengar susurungan karena masuk akal saja bahwa jenazah manusia yang sudah meninggal dunia akan dibungkus dengan kain kafan serta dimasukkan ke dalam liang lahat yang istilah masyarakat Banjar Hulu dipatak.

(2) P: Diarak bukannya pangantin, tapi amun ditanam bukannya kambang, apa nah?

"Diarak bukannya pengantin, tapi kalau ditanam bukannya kembang, apa ya?"

$\mathrm{J}$ : Urang mati

"Orang meninggal dunia."

Pertanyaan susurungan di atas (2) memiliki fungsi untuk mengisi waktu pada saat bergadang menjaga jenazah. Orang yang mendengar pertanyaan susurungan tersebut akan berpikir apa yang diarak tapi bukan pengantin dan kalau ditanam bukan bunga karena dalam masyarakat Banjar Hulu masih ada pengantin yang diarak keliling kampung. Selain itu, pertanyaan susurungan juga apabila ditanam bukan bunga. Padahal sudah jelas bahwa bunga harus ditanam. Hal ini tentu akan membingungkan bagi orang yang baru mendengar susurungan tersebut. Akan tetapi, mudah dijawab bagi yang sudah sering mendengar susurungan tersebut ditanyakan.

Jawaban dari pertanyaan susurungan tersebut adalah urang mati 'orang 
meninggal'. Orang yang meninggal dunia akan dibawa beramai-ramai menuju masjid untuk dishalatkan yang istilah masyarakat Banjar Hulu diarak dengan tandu. Kemudian, mayat tersebut dibawa beramairamai pula ke pemakaman agar jasadnya dimasukkan ke dalam liang lahat yang istilah masyarakat Banjar Hulu ditanam.

Pertanyaan susurungan di atas biasanya dituturkan pada saat begadang menjaga jenazah. Hal ini agar orang-orang yang menjaga jenazah tidak mengantuk dan dapat menjalankan tugasnya hingga pagi hari.

P: Amun urang makan umpat jua makan, amun urang mati umpat jua mati, apa nah?

"Kalau orang makan ikut juga makan, kalau orang mati ikut juga mati, apa ya?"

\section{J: Banalu}

"Benalu"

Pertanyaan susurungan (3) di atas memiliki fungsi untuk mengisi waktu pada saat bergadang menjaga jenazah. Ketika orang yang ditanya dengan susurungan tersebut tentu akan berpikir makhluk seperti apa yang apabila orang makan dia ikut makan dan apabila orang mati maka dia ikut mati. Akan tetapi, jawaban dari susurungan tersebut adalah benalu. Benalu merupakan sejenis tumbuhan yang hidupnya tergantung dari inangnya atau tumbuhan yang ditumpanginya. Apabila inangnya mati, maka benalu pun akan ikut mati.

\subsection{Fungsi Susurungan untuk Dapat Melebihi Orang Lain}

Fungsi sastra lisan susurangan bagi masyarakat Banjar Hulu juga untuk dapat melebihi orang lain. Fungsi susurungan ini dapat dikatakan untuk mengecoh lawan bicara sehingga orang yang mendengar pertanyaan susurungan tersebut akan kebingungan mencari jawaban pertanyaan yang dituturkan. Berikut hasil analisisnya.

\section{(1) P: Iwak napa nah nang paling ganal kapalanya? \\ "Ikan apa ya yang paling besar kepalanya?" \\ $\mathrm{J}$ Iwak bilis bahilim. \\ "Ikan teri memakai helm."}

Pertanyaan susurungan (1) di atas berfungsi untuk melebihi orang lain. Hal ini dapat dilihat dari jawaban susurungan tersebut, yaitu iwak bilis bahilim 'ikan teri memakai helm'. Padahal orang yang ditanya akanberpikir nama ikan yang memiliki kepala paling besar di antara ikan-ikan lainnya. Jawaban susurungan tersebut mengecoh lawan bicara karena sangat bertentangan dengan jenis ikan teri sendiri yang memiliki tubuh kecil. Akan tetapi, jawaban tersebut dapat diterima oleh pendengar karena dikatakan iwak bilis bahilim 'ikan teri memakai helm.' Meskipun hal tersebut sesuatu yang tidak mungkin, akan tetapi pertanyaan susurungan tersebut dapat diterima di masyarakat Banjar Hulu. Hal ini terbukti masih digunakannya pertanyaan susurungan tersebut untuk mengecoh atau melebihi orang lain.

(2) P: Kampung mana nah nang paling banyak babiniannya?

"Kampung mana ya yang paling banyak perempuannya?"

$\mathrm{J}$ : Aluh-aluh.

"Aluh-aluh."

Pertanyaan susurungan di atas berfungsi untuk dapat melebihi orang lain atau mengecoh karena ternyata jawabannya adalah Aluh-aluh 'Aluh-aluh'. Orang yang mendengar pertanyaan susurungan tersebut akan berpikir kampung apa yang penghuninya paling banyak berjenis kelamin perempuan. Akan tetapi, jawaban dari 
pertanyaan susurungan tersebut Aluh-aluh 'Aluh-aluh', yaitu nama sebuah kampung atau desa yang juga menjadi nama sebuah kecamatan di Kalimantan Selatan. Dalam bahasa Banjar Hulu kata aluh berarti perempuan, sehingga jawaban dari pertanyaan susurungan tersebut yang berfungsi untuk mengecoh adalah Aluh-aluh 'Aluh-aluh'. Meskipun, kampung atau desa Aluh-aluh sendiri tidak didominasi penduduk perempuan. Jawaban ini hanyalah sebuah konotasi untuk mengecoh lawan bicara.

(3) P: Kapalanya putih, tagal awaknya hirang, napa nah?

"Kapalanya putih, tapi badannya hitam, apa ya?"

J: Tahi cacak.

"Kotoran cecak."

Dari data (3) di atas, pertanyaan susurungan tersebut seperti mengacu kepada makhluk yang mempunyai kepala putih dan badannya yang hitam. Orang yang mendengar pertanyaan susurungan tersebut tentu akan berpikir makhluk seperti apa yang memiliki kepala putih dan badan yang hitam. Akan tetapi, jawaban dari pertanyaan susurungan tersebut adalah tahi cacak 'kotoran cecak'. Jawaban tersebut tentu mengecoh karena bukan makhluk hidup.Hal ini dianggap oleh penanya bahwa warna kotoran cecak yang terdiri dua bagian, yaitu hitam dan putih. Warna putih yang ada di kotoran cecak tersebut dianggap kepalanya, sedangkan warna hitam dianggap badannya.

\section{Penutup}

Berdasarkan data penelitian yang telah dikaji terhadap fungsi tradisi lisan susurungan bagi masyarakat Banjar Hulu dapat disimpulkan bahwa terdapat tiga jenis fungsi sastra lisan susurungan yang digunakan, yaitu: (1) fungsi susurungan untuk menguji kepandaian seseorang,(2) fungsi susurungan untuk mengisi waktu pada saat bergadang menjaga jenazah, dan (3) fungsi susurungan untuk dapat melebihi orang lain.

Dari hasil penelitian fungsi sastra lisan susurungan ini, disarankan perlu adanya penelitian tentang sastra lisan susurungan yang lebih mendalam lagi. Mengingat, kajian mengenai susurungan ini belum banyak diteliti.

\section{Daftar Pustaka}

Amir, Adriyetti. 2013. Sastra Lisan Indonesia. Yogyakarta: Andi.

Arikunto, S. 2006. Prosedur Penelitian Suatu Pendekatan Praktik. Jakarta: Rineka Cipta.

Asmuni, Fahrurraji. 2014. Sastra Lisan Banjar Hulu. Amuntai: Hemat Publishing.

Bartlet, FC. 1965. Some Experiment on the Introduction of the Folklore. Dalam A Dundes (ed). The Study of Folklore. Englewood, N. J: Prentice Hall. 243258.

Djanandjaja, James. 2002. Folklor Indonesia, Ilmu Gosip, Dongeng, dan Lain-lain. Jakarta: Grafiti Press.

Endraswara, Suwardi. 2009. Metodologi Penelitian Folklor Konsep, Teori, dan Aplikasi. Yogyakarta: Medpress.

2013. Metodologi Penelitian Sastra Epistemologi, Model, Teori, dan Aplikasi. Yogyakarta: Buku Seru.

Hutomo, Saripan Sadi. 1991. Mutiara Yang Terlupakan: Pengantar Studi Lisan. Jawa Timur: Hiski. 
Hapip, Abdul Djebar. 2006. Kamus Banjar Indonesia. Banjarmasin: Grafika Wangi Kalimantan.

Kawi, Djantera, dkk. 2002. Penelitian Kekerabatan dan Pemetaan BahasaBahasa di Daerah Indonesia, Provinsi Kalimantan Selatan. Jakarta: Pusat Bahasa.

Mugeni, M, dkk. 2008. Kamus Bahasa Banjar Dialek Hulu-Indonesia. Banjarbaru: Balai Bahasa Banjarmasin.

Sudikan, Setya Yuwana. 2001. Metode Penelitian Sastra Lisan. Surabaya: Citra Wacana.

Taum, Yoseph Yapi. 2011. Studi Sastra Lisan Sejarah, Teori, Metode dan Pendekatan Disertai Contoh Penerapannya. Yogyakarta: Lamalera.
Teeuw, A. 1988.Sastra dan Ilmu Sastra: Pengantar Teori Sastra. Jakarta: Pustaka Jaya-Giri Mukti Pasaka.

Tisnasari S dan Ahmad Supena. 2013. "Tradisi Lisan Ziarah Kubur Eyang Dalem Cikundul di Kabupaten Cianjur (Sebuah Kajian Bentuk Fungsi dan Makna Folklor pada Cerita Rakyat)" dalam Folklor dan Folklife Dalam Kehidupan Dunia Modern: 160-168. Yogyakarta: Ombak.

Yayuk, Rissari. 2009. "Sastra Lisan Banjar: Cucupatian" dalam Bunga Rampai Hasil Penelitian Sastra: 121-138. Banjarbaru: Balai Bahasa Banjarmasin.

. 2011. Cucupatian Banjar. Banjarbaru: Balai Bahasa Banjarmasin. 